\title{
Sympathy for the devil: Reconsidering Ernst Mach's empiricism
}

\section{Erik C. Banks}

\section{Metascience}

ISSN 0815-0796

Volume 21

Number 2

Metascience (2012) 21:321-330

DOI 10.1007/s11016-012-9672-3

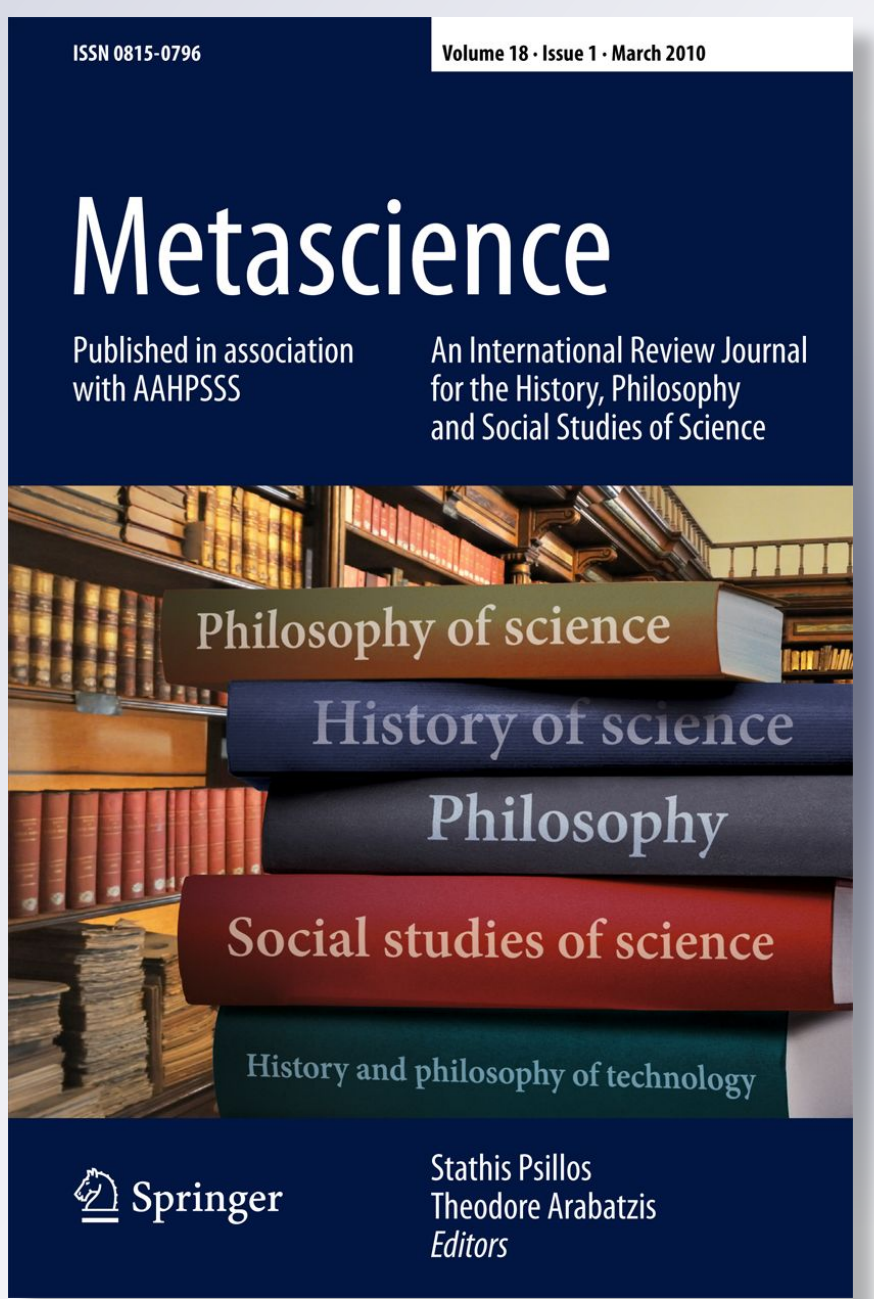

Springer 
Your article is protected by copyright and all rights are held exclusively by Springer Science+Business Media B.V.. This e-offprint is for personal use only and shall not be selfarchived in electronic repositories. If you wish to self-archive your work, please use the accepted author's version for posting to your own website or your institution's repository. You may further deposit the accepted author's version on a funder's repository at a funder's request, provided it is not made publicly available until 12 months after publication. 


\title{
Sympathy for the devil: Reconsidering Ernst Mach's empiricism
}

\author{
John Blackmore, Ryoichi Itagaki and Setsuko Tanaka (eds): Ernst \\ Mach's Prague. Bethesda and Tokyo: Sentinel Open Press, 2010, \\ 476pp, \$40.00 HB \\ John Blackmore, Ryoichi Itagaki and Setsuko Tanaka (eds): Ernst \\ Mach's philosophy: Pro and Con. Bethesda and Tokyo: Sentinel \\ Open Press, 2009, 252pp, \$25.00 HB
}

\section{Erik C. Banks}

Published online: 9 March 2012

(C) Springer Science+Business Media B.V. 2012

Aristotle claimed that the sign of an educated mind was the ability to entertain a thought without accepting it. Yet, as we all know, sometimes we encounter a position so foreign to our own ways of thinking that even entertaining it is impossible. John Blackmore, over his long career of writing about the life, work and influence of Ernst Mach, has never been able to see anything of value in Mach's philosophical writings, and what is more, his historical coverage of Mach's career is often punctuated with tirades against what Blackmore calls Mach's "phenomenalism," the belief in the reality of human sense experience and literally nothing else. Blackmore reiterates that view in Ernst Mach's Philosophy Pro and Con, his first book devoted exclusively to Mach's philosophy, along with a recent offering about Ernst Mach's Prague. In previous work, Blackmore has identified as an historian and claimed to avoid taking sides in philosophical disputes, but this has never been entirely true. It seems he cannot resist promulgating an erroneous, though widely shared, reading of Mach's philosophy that has damaged Mach's reputation for more than one hundred years, and one that I have tried to set straight in my (2003) and will again in this essay.

Before getting to that, I will say that Blackmore's work purely as an historian has been exemplary and does certainly demonstrate his ability to serve as a neutral judge. He has done a great deal to get all of the evidence out there and even publishes documents by Mach himself and writings by others, which do not square with Blackmore's reading of Mach's philosophy. Since his 1972 biography of Mach, Blackmore published a selection from Mach's Correspondence in 1985 (with Klaus Hentschel), an excellent collection of essays called Ernst Mach-A Deeper Look in 1992, and Ernst Mach's Vienna in 2001. A fifth volume, called Ernst

E. C. Banks (西)

Wright State University, 3640 Colonel Glenn Hwy, Dayton, OH 45435, USA

e-mail: Erik.Banks@wright.edu 
Mach's Science (2006), was published in Japan by Tokai University Press. Recently, Blackmore has been releasing self-published volumes, along with his collaborators Ryoichi Itagaki and Setsuko Tanaka. The quality of these collections is not as high as that of the other volumes, which were presumably strengthened by the peer review process. Nevertheless, there are many good things here, including detailed materials on Mach's assistants and students in Prague, with a supplemental detailed essay by Emilie Těšínská, an account of Mach's work on shock waves, citing recent work by Christoph Hoffmann, and a chapter on the relationship between Mach and the chemist František Wald, including a translation of their correspondence. Blackmore has also included a useful catalog of Mach's correspondence. The only fault I have with Blackmore the historian is his neglect of the Notizbücher, which reveal Mach's mind at work. Blackmore says that the Notebooks are misleading, since we only have them dated roughly by year, and no one has keyed them exactly to the time and place of writing. Blackmore has used this excuse to dismiss notebook entries in which Mach acknowledges elements not given in sensory observation, doubts about his opposition to atoms, and other entries that fill out and inform his published writings. It is true that these Notebooks cover a long development, with many twists and turns and changes of mind, but they are surely important documents for those who would understand Mach's philosophy.

As I said, this has never been Blackmore's goal, but he has also refused to remain neutral on the matter, expressing himself on philosophical matters of epistemological realism versus empiricism, with no serious scholarly study of the positions he defends or attacks. These rumblings and fulminations would not be acceptable as professional contributions to philosophy. He simply describes his own position of indirect realism and says that all other views are absurd because they are unscientific, as if there were only one philosophy of science, a distortion he would never fall victim to if this were his area of expertise. He gives grotesque counterexamples to his strawman "Machian phenomenalism," such as the fact that objects grow and shrink in the visual field, which Blackmore thinks forces Mach to believe that the objects really are of different shapes and sizes. But this is just a howler. Mach answers this objection succinctly in the Analysis of Sensations (1959) by distinguishing the sensory appearance from its cognitive interpretation as an object in space, and indeed one that appears perspectively from different points of observation, as it should. Mach also says that there are no "sense illusions" properly speaking because sense appearances, as they are given, do not represent anything truly or falsely; again, this is a matter of further cognitive inference from the appearance to the object it is supposed to represent. Likewise, Blackmore faults Kant's empirical realism and transcendental idealism about space because we can take photographs of objects when no one is looking and the objects are still pictured in space and time. But that's what Kant means by calling space empirically real. A spatio-temporal representation of nature is always possible and always objectively valid, not just when someone is there to observe it. Space and time are transcendentally ideal simply because this is not the only objective representation of nature; other thinking beings may use different, equally objective, representations. Space and time are thus objective, but not uniquely so. Blackmore's 
"subjective idealist" reading of Kant is a beginner's error, easily corrected by studying the many fine scholarly works about the Critique.

Of course, many people trained in other fields hold forth on philosophy; outsiders believe philosophy is a subject where no special training or knowledge is needed and only opinion reigns. Even brilliant scientists like Stephen Hawking or Richard Feynman never seem to get much beyond "if a tree falls..." In the case of Mach, this was decidedly not so. Despite his own protestations to the contrary, Mach was a major philosophical thinker and natural philosopher who devoted considerable time and effort to developing his philosophico-scientific worldview. His primary emphasis was not on sensations per se but on monism, on one philosophical and scientific conception of the world, which led him to include sensations among physical events, considering sensation as real as energy, force or a physical body, where materialists, and representative indirect realists alike, had dismissed sensations as mental, subjective and unreal. Bertrand Russell recognized Mach's "service to philosophy" as the idea that "what is experienced may be part of the physical world and often is so" (Banks 2003, 151). Sensations thus have a double interpretation, as experiences and as physical events.

But Mach also thought that mind-independent elements of the physical world existed, similar to sensations, but bound up in mind-independent complexes by dynamic, functional relations with each other, governed by laws (Banks 2003). Sensations are just a special class of these general elements when they occur in the human nervous system, which is why he $(1959,16)$ explicitly recommends using the more general word "element" over the word "sensation" to head off the misunderstanding. Mach was thus the originator of a lesser known but important philosophical position, sometimes known as neutral monism, which influenced William James and Bertrand Russell and which has made a recent comeback in the philosophy of mind (Banks 2010). Despite these ties, and plainly realist tendencies, Mach is still associated with the logical empiricism of the Vienna Circle, originally the Ernst Mach Verein. Authors from Paul Feyerabend to Friedrich Stadler to myself have fought against this reading by carefully distinguishing Mach's nuanced position from the cruder logico-linguistic positivism of Carnap and the Circle. As we have urged, Mach's philosophy deserves to be treated with far more respect than is evidenced by historians and philosophers, who still almost universally regard him as a rather simplistic positivist, phenomenalist, idealist (pick your label), forerunner of the Vienna Circle. That this is still the state of play, no thanks to Blackmore himself, even after so much work has been done to correct it, does not say much about our appreciation of such a pivotal historical figure. And Mach is indeed a major figure. Even if the subtleties did not always come across to his readers, then as now, there is no doubt that Mach's empiricism played a major role in twentieth century science by any standard: both Einstein's relativity of simultaneity and Heisenberg's representation of the atom as a matrix of "observable quantities" were probably influenced in some way by Mach, even while he simultaneously hindered the acceptance of the atomic theory and the kinetic interpretation of thermodynamics through his misguided belief that atoms were metaphysical Kantian things in themselves that could never be observed, not even in principle (Banks 2003, 12-13). When he was disabused of this bizarre notion, by observing scintillations on a 
screen in 1903 or thereabouts, he seems to have accepted atoms, finally, as "not occult," but little objects continuous with sensory experience, although he may still have regarded his elements as more fundamental than atoms at some deeper level, perhaps in their innards (Banks 2003).

Now let's do a little harmless historical comparison. Would Mach have preferred Heisenberg's matrix atoms to the billiard ball model? Mach reached his own negative appraisal of atoms in 1872, and even earlier, by reflecting that the spectral lines of the chemical elements required more degrees of freedom of vibration than simple billiard ball atoms could possibly execute in three dimensions. His correspondence with Wald in Ernst Mach's Prague indicated that he still approved of such a view, relating observable quantities in a multidimensional tabular arrangement as a substitute for atomism. Does that make Mach an actual precursor of Heisenberg and the quantum mechanical atom, a step beyond Planck and Boltzmann's indirect realism? Not by a long shot. But as my little example shows, it is easy to turn the tables by picking your period in the history of science, picking your heroes, picking your preferred philosophy of science and its triumphs, as Planck and Boltzmann are Blackmore's heroes. But should one have heroes and villains in such a complex Shakespearian story with so many reversals of fortune? In the period of Einstein and Perrin, a realist philosophy of science seems the way to go. In the period of the quantum theory and the 1927 Solvay Conference, Heisenberg's and Bohr's empiricism triumphed over Einstein's indirect realism, culminating in Bohr's refutation of EPR, not to mention the later work by J. S. Bell, which put another nail in the coffin of indirect realism, at least about hidden variables. A philosopher of science like Arthur Fine (placed in the "pro-Mach" camp by Blackmore), who draws his inspiration from this later period, can thus be fully informed about the facts of science and be anti-"realist." Lesson: science does not vindicate any one philosophical view: positivism, indirect realism, historico-constructivism, name your poison. Blackmore is just wrong to claim that the indirect realism of Planck, Boltzmann and Einstein and his other heroes is the only legitimate view. He is just not representing the philosophy of science in a professional way.

I have not even mentioned what many consider Mach's greatest impact on science, the infamous Mach's Principle which played such a key role in Einstein's thinking about general relativity, but which Einstein was forced to discard. This is a whole area of study, and there are so many versions of the principle that the reader must turn to a volume like Barbour and Pfister (1995) for an overview. The coinage "Mach's Principle" is certainly not Mach's own, nor should he be associated with these many later formulations. As John Norton (in Barbour and Pfister 1995) pointed out, Mach never proposed that inertial effects, say on Newton's rotating bucket of water, were caused by the gravitational pull of distant bodies, through instantaneous action at a distance, as Einstein believed for a time. ${ }^{1}$ Blackmore seems not to know of Norton's essay, instead falling headlong into Einstein's reading in an essay he appends to Ernst Mach's Prague. It also never occurs to him that Mach might have

\footnotetext{
1 He only suggests the idea very vaguely: "the natural investigator must feel the need of further insight of knowledge of the immediate connections, say of the masses of the universe. There will hover before him as an ideal an insight into the principles of the whole matter, from which accelerated motions and inertial motions result in the same way" (1960, 296).
} 
rejected this reading when Einstein communicated it to him in a letter. Blackmore thinks Mach rejected Einstein's general theory because he rejected all theories, a wildly irresponsible charge, which can be refuted with the simplest look into any of Mach's scientific books or papers. Conveniently, when one resorts to simplistic accusations, one does not have to do the hard work to examine the deeper scientific issues and arguments. On a closer read, Mach merely said that the two cases, rotating universe/still bucket and rotating bucket/still universe, were the same case described twice but only given once $(1960,284)$. Inertial resistance in one reference frame is replaced by a gravitational force in another reference frame, but he is silent as to why, and he certainly never says that gravity acts instantaneously at a distance from the distant bodies to the bucket. He merely thinks that there is no absolute frame of reference, or state of motion, and so the invariant physical phenomena will rearrange themselves so that the two situations are symmetrical, which Norton calls the redescription argument. Mach also wished for an elimination of space and time from physics, first by relativizing accelerated reference frames, and then by reformulating physical laws without mentioning space and time at all (Norton in Barbour and Pfister 1995; Banks 2002). Today, I prefer to think of Mach as recommending a principle of physical invariance coupled with a universal relativity of reference frames, in the tradition of Leibniz. In Specimen Dynamicum, Leibniz showed that an elastic collision, say between two billiard balls, can be relativized even to accelerated reference frames, where the elastic deformation of the ball can be viewed either as an acceleration or a deceleration and what he called the passive (inertia, elasticity) and active forces (kinetic energy) switch places accordingly. Einstein's own achievement in special relativity, of relativizing the electromagnetic field to the Lorentz transformations, follows the same strategy. The field exchanges its electric and magnetic field components depending on the relative motion of the observer, showing that the physical phenomenon of the combined electromagnetic field is indifferent to the motion of the reference frame from which it is viewed. The principle of equivalence is yet another example of an exchange between inertial resistance to acceleration in one localized reference frame and the presence of a uniform gravitational field arising out of empty space in the other. This is supposedly non-Machian because there is no source body for the fictitious uniform gravitational field (Renn 1994), and yet it conforms completely to the spirit of Mach's defense of universal physical invariance, since there is no absolute space either. There is an invariant inertial-gravitational field, as in the case of electromagnetism and the Lorentz transformations; but while this field fills space, or is space, it is not absolute, nor does it require action at a distance from distant masses or bodies, since its inertial-gravitational effects are purely local. I do not know if Mach could have accepted Einstein's much later concept of space as the field, even a field invariant in all moving reference frames. The field concept was not so well established in his day, but Mach, full of surprises as ever, was capable of speculating that the medium of space might be responsible for inertia like a kind of molasses, as long as it was reference-frame invariant molasses. He even says in the Mechanics that he is open to the concept of an inertia-producing medium, as long as it is not identified with Newton's absolute space (1960, 282-283). It now seems to me that a physically invariant inertial field would indeed have been music to his ears. 
I now want to pass to Blackmore's book Ernst Mach's Philosophy: Pro and Con. This is a collection of reactions to Mach's philosophy, which the editors have grouped into those they feel are supportive of Mach and those that are in opposition to him. Since these quotations are all available from other sources, including my own essay on functionalism that was reworked as a Synthese article (Banks 2004), I will concentrate on the three introductory essays by Blackmore specifically about Mach's philosophy. As I said, Blackmore characterizes Mach's position as "phenomenalism," which is the view that only human sensations exist, that theories are nothing but economized lists of individual observations, and that the external world of mind-independent space, time and objects does not exist except as a "thought symbol" for groupings of human sensations. Blackmore contrasts phenomenalism with what he calls indirect realism, sometimes representative realism when he wishes to emphasize epistemology. On this view, we subscribe to a basic dualism: there is a real, mind-independent and objective external world of atoms, space and time, law and causality on which scientists can agree and of which they obtain knowledge through experiment and theorizing. On the other side are sensations, which differ from observer to observer, and are mental. We have only an indirect picture of the real world in our sensations, which, though mental, are linked somehow to external reality via a causal chain, or representative theory of perception. According to Blackmore, all scientists Descartes, Galileo, Locke, Newton, Planck, Einstein, along with all right-thinking "practical people"(?) are partisans of indirect realism. It is true that we all fall backward into naïve realism from time to time, mistaking our sensations of objects for the real objects external to our minds, but, like Empedocles, we quickly learn that what we see and taste is different from what others see and taste in the same object, and so we learn to be indirect realists instead.

So far as it goes, indirect realism does accurately describe the commonsensical epistemological starting point of most philosophers, including empiricists like Mach. So what changed? In fact, Mach tells us clearly that after reading Kant's Prolegomena at fifteen, he began to have doubts about whether nature an sich really had to be pictured in a spatio-temporal way, as little atomistic objects moving around in space and time. Kant of course had stressed the transcendental ideality of space and time when these forms of human sensibility and imagination were applied to things in themselves. That Kantian idea would always be important for Mach, who stressed that we should not naively extend our sensory imagination and intuition to nature, lest we make unconscious "metaphysical" or disguised sensory additions to our science, adding excess baggage and misleading us. ${ }^{2}$

Mach soon had a powerful experience of monism, which convinced him to toss out the thing in itself and embrace one undivided view of reality, in which human sensations of color or sound could be considered just as real as the physical objects in the external world, and in which there would be no dualism between the mental and the physical. At the same time, the central problem of the causal or

\footnotetext{
$\overline{2}$ As I have written in my (2003), 'metaphysics' for Mach does not mean unobserved, or abstract, but rather refers to this error of injecting sensory imagery and visualizations into scientific results and models which the results do not sanction.
} 
representative theory of perception would be solved, since there would be nothing problematic about a world where sensations interacted with objects sharing the same world, as opposed to the Cartesian problem of a causal relation bridging two utterly separate realms of the mental and the physical. Mach's monism thus made it impossible for him to accept the indirect realism or interactionism of the seventeenth century philosopher scientists. He had to find for himself a unified scientific world view in which sensations, which he studied extensively in his psychophysics (of light, color, sound, time, space and movement sensation), were just as real as the objects of the physical world. Contemporary philosophers of mind rediscovered this problem one hundred years later under the rubric of physicalism and qualia, asking whether sensations are not, after all, real and, if they are, how such things as colors and sounds can fit into a physicalist world view, which seems to have no room for them. Then, as now, this monist intuition puts pressure on orthodox physicalism, demanding a more inclusive view of the physical, which I have elsewhere called enhanced physicalism (Banks 2010). I trace the basic arguments for an enhanced physicalism back to Mach, as their originator. ${ }^{3}$

At about the same time, Mach began his researches into the history of science. He began to be suspicious of a priori knowledge and of the use of auxiliary models or picture thinking. Mach showed ruthlessly one by one, in the case of Archimedes' law of the lever, the principle of the superposition of forces, of virtual velocities, Helmholtz's purported proof of the conservation of energy, how the argument made empirical presuppositions, often of a very subtle nature, and presupposed exactly what it claimed to prove a priori. So complete was Mach's demolition of these arguments that one never hears the law of inertia or conservation of energy cited as a priori principles, as was quite common up until Mach's time. Another lesson he learned from his historical studies was that the various models scientists use to visualize and obtain their results often prove to be badly off the mark. The attempt to picture heat as an actual fluid called "caloric" had permitted the derivation of several results including Carnot's stunning deduction of the maximum efficiency for heat engines. And yet caloric did not exist, the model Carnot used for visualization of heat flowing "downhill" from hot to cold like water flowing over a mill while conserved in quantity, later had to be given up as a false picture or analogy, refuted by the experiments of Joule and Mayer. The history of science is replete with examples of subtle fluids, elastic media, billiard balls, hidden springs and gear wheels, which turn out to be misleading analogies, or picture thinking. Mach was always suspicious of those extras, trying to stick as much as possible to what he called "phenomenological physics." Phenomenological physics was not a list of individual experiences, nor was it inductive, but rather could involve highly general, abstract and theoretical postulates of experience such as the first and second laws of thermodynamics, the principle of least action in mechanics, or Fermat's law of least time, independent of any realizing mechanisms, pictures, stories or model of the underlying processes. It is very wrong to say, as Blackmore does, that Mach disdained theories. No, he extolled them, and the more general and unifying the better. True, Mach failed to see that in the case of atoms the explanatory story was

\footnotetext{
${ }_{3}^{3}$ Although Leibniz and Kant deserve some credit, as do Richard Avenarius and W. K. Clifford.
} 
beginning to converge on the same picture from several different quarters, although he purportedly said to Einstein that he was willing to countenance the atomic hypothesis as a unifying explanation for different ranges of phenomena, since this did not violate his view of the role of theories (Blackmore 1992, 152-153, quoting Phillip Frank). That debate still continues in some quarters, at least between those empiricists who still emphasize the explanatory unification of natural phenomena under the fewest number of laws, hypotheses and postulates, and those entityrealists who believe that science is the discovery of unobserved entities and mechanisms, the erector set of the universe. Both sides have their historical victories and embarrassing failures, and most scientists pursue both goals simultaneously. There are also more advanced empiricists, such as Bas Van Fraassen and Arthur Fine, who take a "natural ontological attitude" of realism about entities and models (similar to Kant's empirical realism), from the inside, or from the state of present knowledge, say about electrons, but who reject transcendental claims about the world an sich, or about future theories, God's eye views or what have you.

Mach's solution to the problem of the unity of science took the form of a new kind of monism, which, as noted already, Russell later called "neutral monism" (Banks 2003, 2004, 2010). Materialist monism says that all is matter, making no room for mental phenomena. Idealistic monism says that all is an idea or a sensation in a mind, making matter a mere bundle of sensations and denying a mindindependent external world. Mach proposed a third option. The solution, Mach said, was to adopt elements, which started out as forceful, energetic qualities in dynamical relations to one another, and which he had found in the philosophy of $\mathrm{J} \mathrm{F}$ Herbart, one of his early mentors (Banks 2003). Some of these elements came together in combination and formed human sensations, in manifolds of color, sound, sight, touch. Others of these elements formed mind-independent physical objects not dependent on minds, but causally continuous with sense experience, unlike the Ding an sich. In themselves, the elements were neutral, but became mental or physical depending on the kind of complex they were involved in. And really there is not much difference between complexes either except for the names; really, they could all be considered natural elements and complexes. In each case, as Mach insisted, we have to do with nothing but elements in various functional relations with each other. The added elements of the world independent of the mind are for Mach, not a new or foreign addition. Behind the world of observation, one simply finds more observations (figuratively speaking), more interactions, more elements of the same kind as those we encounter in experience. For Mach, there never was a line drawn between these world elements and the ego and its sensations. As Mach clarifies in his late masterpiece Knowledge and Error (1976), you get such artificial barriers between ego and world by dividing up what is really an indivisible fabric of experience-reality. I thus think of Mach's view as a kind of realism, a realistic empiricism, enhanced by the addition of realistic mind-independent elements. As I have shown in detail, Mach's position is perfectly consistent with James' radical empiricism and Russell's neutral monism, with very minor differences (Banks 2003).

In his Analysis of Sensations, and in the conclusions to all of his scientific books, Mach describes laying out the contents of the universe, sensations in the mind right 
alongside the physical elements of the brain, body and the physical environment on one giant causal network, linked together by functions of various kinds to be discovered by science. What is true in indirect realism is still true here; there is indeed an indirect causal chain between elements making up external objects and sensations in the human nervous system. These objects are continuous with perception and constructed in an empiricist way from the unobserved elements, not bundles of present sensation, as Blackmore believes. But more abstract functional relations are permitted than spatio-temporal ones, including tabular and matrix-like arrangements. We are not bound to mental images or visualizations. There is no dualism, but there is a direct experience of the natural world in sensations, which exist in their own right, and not just mentally. Everything one wanted from indirect realism is preserved and everything that is unwanted, the dualism, the interactionism, the lack of causal continuity, the picture thinking, is eliminated.

It is a stunning piece of work and does induce an awesome sense of calm and contemplation. But one question remains: what are these elements? Tiny energy quanta? Event particulars, a la Russell? Leibniz's petites perceptions? Feyerabend (1984) thought Mach's elements were "even more fundamental than atoms." Mach thought the question was open to future investigation, not stipulation; so, true to form, he never answered it. Predictably, others rushed into fill the void. Elements are just another word for sensations, said Lenin in Empiricism and EmpirioCriticism, mere wordplay. I suppose the majority of interpreters have done the same: read Mach, scratched their heads at this new term "elements" and concluded that elements are just another word for sensations for what else could they be? And they cannot be convinced otherwise, since, pace Aristotle, they cannot conceive what is inconceivable for them. Like everyone, I have my own blind spots in philosophy: I do not get medieval theology, or why Hume thinks I cannot rationally prefer the scratching of my little finger to the destruction of the world (and my little finger). So I stay away. I do not have a dog in those fights. I think Blackmore would have done better to stick to the historical work at which he has succeeded so well. Scholars of Mach's works (including the present author) have much to thank him for. Scholars of Mach as a philosopher must look elsewhere.

\section{References}

Banks, Erik. 2002. Ernst Mach's 'new theory of matter' and his definition of mass. Studies in History and Philosophy of Modern Physics 33: 605-635.

Banks, Erik. 2003. Ernst Mach's world elements: a study in natural philosophy. Dordrecht: Kluwer Academic Publishers.

Banks, Erik. 2004. The philosophical roots of Ernst Mach's economy of thought. Synthese 139: $23-53$. Banks, Erik. 2010. Neutral monism reconsidered. Philosophical Psychology 23: 173-187.

Barbour, Julian, and Herbert Pfister (eds.). 1995. Mach's principle: Newton's bucket to quantum gravity. Boston: Birkhäuser.

Blackmore, John (ed.). 1992. Ernst Mach: a deeper look: Documents and new perspectives. Dordrecht: Kluwer Academic Publishers.

Feyerabend, Paul. 1984. Mach's theory of research and its relation to Einstein. Studies in History and Philosophy of Science, Part A 15: 1-22. 
Mach, Ernst. 1959. The analysis of sensations and the relation of the physical to the psychical. (Fifth edn.) (trans: Williams, C.M., Sidney Waterlow). New York: Dover.

Mach, Ernst. 1960. The science of mechanics in its development. 6th English edition. (trans: Thomas McCormack). Chicago: Open Court.

Mach, Ernst. 1976. Knowledge and error. (trans: Thomas McCormack, Paul Foulkes). Dordrecht: D. Reidel.

Renn, Jürgen. 1994. The third way to general relativity. Max Planck Institut für Wissenschaftsgeschichte, pre-print no 9. 